\title{
MedienPädagogik
}

www. medienpaed.com

Zeitschrift für

Theorie und Praxis

der Medienbildung

ISSN 1424-3636

Themenheft Nr. 24: Educational Media Ecologies

\section{Education, Media and the End of the Book Some Remarks from Media Theory}

Rainer Leschke and Norm Friesen

\begin{abstract}
This paper sketches out an understanding of contemporary educational forms and practices from a vantage point afforded by recent German media studies. In so doing, it introduces a number of concepts from continental media theory. With the book-both as an artifact and an epistemic metaphor - in evident decline, what is taking its place is not any one new medium, but rather a radically new kind of media systematicity. By relentlessly reducing all content (e. g., music, film, text) to ones and zeros, digitization effectively erases the material characteristics of separate media forms, leaving behind only their conventionalized aesthetic qualities and forms. The paper builds on these arguments by concluding that the symbolic competencies which once constituted the core of all education (reading, writing, 'rithmatic) are increasingly at odds with performative and stylistic abilities integral to this new mediatic order.
\end{abstract}

\section{Introduction}

All cultures are interpenetrated and structured by their media. From the drum languages of West Africa through medieval manuscripts to today's global digital networks, media mediate culture, shaping social relations, both in terms of what is communicated and how such communication occurs. All cultures are in this sense media-cultures, and it further follows that all forms of involvement with culture, including educational and formative participation, are unavoidably also engagements with its media. Becoming part of a culture, opening up new cultural horizons, and developing and problematizing these further, are all processes that are mediated through media. To be able to reflect on the mediality ${ }^{1}$ of cultures can consequently be seen as one of the most elementary forms of reflexive cultural engagement.

Processes of education and formation, from formal schooling to techniques of self-help, represent forms of engagement with one's culture and with oneself that are always also engagement with the particular mediality of cultural communication. The study of culture has long ignored the significance of media in this sense. Instead of examining the production, circulation and remediation

1 The chapter uses a vocabulary of «mediality» and «mediation» that is introduced in Norm Friesen and Theo Hug, «The Mediatic Turn: Exploring Consequences for Media Pedagogy.» In Mediatization: Concept, Changes, Consequences, ed. Knut Lundby, 64-81. New York: Peter Lang, 2009. 
of the Victorian novel or the Elizabethan theatre, for example, it has tended to study «Dickens» or «Shakespeare», as if the mediatic and material nature of their cultural production was either invisible or tertiary. This forgetting of media and mediation (Medienvergessenheit) has applied not only to the conditions of culture and its appropriation, but particularly to the close connection of education and socialization to media. Socialization and conscious self-formation are not only medially mediated, but have this condition of mediation itself as a subject of conscious reflection. Understanding processes of formation in and through media is dependent on understanding media themselves - their theory, analysis, history, and aesthetics. ${ }^{2}$

This paper represents an initial foray in this direction. It takes aspects of German media studies (e.g., see Horn, 2008) related to media history, theory and aesthetics, and sketches out one particular way of understanding their relevance to contemporary education. In so doing, it introduces a number of notions important to theories of media that recently been developing in German-speaking Europe. Besides Medienvergessenheit, these include the notion of a Leitmedium, of media-systems, of Pierre Bourdieu's understanding of social distinctions, and also the belief that a given medium constitutes a Foucauldian «apparatus» or dispositif. It begins, however, by explaining the generally negative response of those in education to new media forms by developing the notion of the gradual and often conflicted integration or "enculturation» of new technologies into the social order. Like the musical Leitmotif, a Leitmedium serves as a repeating and guiding example for such a process. It acts as a standard to determine what is valuable and desirable in cultural contexts offering multiple, competing media or within complex «media-systems.» ${ }^{3}$ The medium of the book has historically served as precisely such a Leitmedium in educational (and other) contexts, but its dominance as a medium, together with associated practices of reading and the traditional authority of the author, is clearly in decline. What is taking their place is not so much the characteristics of a new Leitmedium as a radically new and distinctly digital way of organizing media and media-systems. By relentlessly

2 These initial two paragraphs have been freely adapted and translated from the document with the permission of the authors: R. Leschke, P. Spangenberg, and C. Tholen (2012). «Medienkultur und Bildung: Positionspapier der GfM.» www.gfmedienwissenschaft.de/gfm/gfm/index.php?NID=38 (abgerufen am 5.12.2013).

3 The history of the concept of a Leitmedium is reconstructed in: Ligensa, Annemone, Daniel Müller, and Peter Gendolla, Hrsg. Leitmedien. Konzepte - Relevanz - Geschichte. Band 1. und 2, (Medienumbrüche 31/32). Bielefeld 2009. Michael Giesecke provides in his 2002 book From the Myths of Book-Culture to Visions of the Information Society the following explanation: «Up to this point, every high-culture in history has chosen a Leitmedium. For example, the word, rather than the dance will stand at the beginning of a culture which understands itself as a culture of writing. And insofar as a culture chooses a particular medium as its totem, others are devalued and excluded. Those trained in the art of writing, for example, acquire power and prestige. Even though they would not be permitted to dance, they would be the ones to determine which types of dance and motions would be allowed and forbidden» (227). 
reducing all media contents to ones and zeros, digitization brings conventional media forms and formats into new interrelationships, effectively erasing their material characteristics as separate media, and foregrounding their individual formal qualities as aesthetic conventions. The paper concludes by exploring how the symbolic competencies which once constituted the core of all education (reading, writing, 'rithmatic) are increasingly at odds with performative and stylistic abilities integral to these new media forms.

\section{Of an Apocalyptic Tone ...}

When it comes to new media technologies, educators clearly tend towards the apocalyptic rather than the utopian end of the spectrum. Strident critiques of media are still a part of the conventional "apocalyptic» tone of pedagogical discourse. This is based on an elementary reflex, to which parents and others in authority are decidedly sympathetic: The response of uncertainty and even fear in the face of that which is radically novel.

The first reflexive intervention of this kind, of which we have at least some reliable knowledge, appears to be Plato's critique of writing. It is not by chance that this critique was advanced by representatives of an educational institution, specifically Plato's academy. And that these educators very clearly privileged oral discourse as the medium of instruction has had lasting consequences. That oral discourse now serves as a common standard for media and engagement with it can be traced back to the powerful critique found in Plato's Phaedrus:

Writing is inferior to speech. For it is like a picture, which can give no answer to a question, and has only a deceitful likeness of a living creature. It has no power of adaptation, but uses the same words for all. It is not a legitimate son of knowledge, but a bastard, and when an attack is made upon this bastard neither parent nor anyone else is there to defend it. $(1892,402)$

Plato's negative intervention appears to have been enormously successful. Indeed it can be seen as helping to create, through negative implication, a particular ideal for media, one that is closely related to the notion of Medienvergessenheit. The implication that media should be as close as possible to speech (avoiding the characteristics of its "bastard son», writing) implies that any medium may be regarded as effective and positive when it is as invisible as possible: Oral communication, something so natural and ubiquitous that it does not appear to be a medium at all, is the "gold standard» by which all other media are measured. The more they, too, can approximate the adaptability, interactivity and thus the perceived legitimacy of speech, the more they disappear behind the meaning they convey and defend, the more exemplary they are as media. This further implies 
that the primary pedagogical a priori with which media are marked is consequently a negative one: Media are defined by their self-effacement, they work best when they achieve their own disappearance. As Sybille Kraemer (2008) says, effective media are aesthetically self-neutralizing; their efficient «implementation feeds on their own withdrawal» (Der Vollzug von Medien zehrt von ihrem Entzug; 28).

That educational media-apocalyptic diagnoses regularly presuppose this Medienvergessenheit is itself often completely ignored and forgotten. «Apocalyptic» media are always only the new and unfamiliar media of others. One's own media are valorized and naturalized, and consequently rendered invisible. The characteristics of one's own privileged media are also almost completely repressed. That oral discourse is an exemplary medium, indeed that it is a medium at all is taken by Plato as so self-evident that its characteristics as a medium are immediately forgotten. One can hardly accuse Plato of single-handedly initiating that dialectic of the repression of accepted media and the rejection of those less invisible, «un-enculturated» forms. However, the fact that this gesture is repeated with astonishing regularity and frequency should give some pause for thought.

Obviously there is a close connection between this Medienvergessenheit and anxious aversion to new media forms. Media are first of all capable of becoming fully naturalized. As a result, they can completely disappear from our purview. Media themselves are enculturated; and as thus as a part of such a historical culture they become inconspicuous, they become an invisible part of the infrastructure of a culture as the transparent yet indispensable infrastructure of radio waves carrying phone calls, GPS coordinate information or radio programs. In the processes of the reproduction of a culture, these enculturated media are not only deployed as a taken-for-granted part of the lifeworld, their use is mediated and taught without any explicit attempts to explain and legitimate their constitution as media. Enculturated media are consequently organic constituents of processes of education and self-formation, and they fulfill this role in two senses: they legitimate themselves by making themselves invisible, at the same time, they serve as the means by which cultural goods are received, understood and reproduced.

Conversely, non-enculturated media inevitably attract attention: By virtue of their very constitution as «new» media, they appear to overtly infect cultural infrastructures, and as such appear to those invested in those infrastructures as threatening. Using metaphors of travel to characterize German culture, Hans Magnus Enzensberger once remarked that «apocalypse is a part of our ideological carry-on» $(1978,74)$. One could say that this baggage is more cumbersome but all the more carefully guarded in the case of teachers and academics. However in this case, the apocalypse in question is not religious or cosmic event but a cultural or more specifically media-cultural one. After all, specific incarnations of culture appear, disappear and mutate with some regularity, while the cosmos itself 
remains relatively intact. And in some cases, the changes are not altogether bad. For example, the bourgeois subject, which still anchors almost all pedagogical discourse, owes its existence to one of the most recent of these changes: It emerged as the result of the printing press, and in response to corresponding changes in the structure of the public sphere.

Education, however, sees in new media nothing less than a media-technological and cultural apocalypse of the existing social order. Also, other stakeholders in this social order may join in, forcefully rejecting all that which new media both connote and denote. The Roman Catholic Church and universities reacted in precisely these ways to the new medium of the printing press - namely, through censorship and the inquisition. On the other hand, Protestants served as the social carriers and beneficiaries of this new medium. This led not only to the rise of protestant bourgeois morality (which can be said to have become a generic part of the global West), but also introduced a new logic for control and decision-making: This is a logic that proved extremely efficient in economic terms, and that allowed for the finest distinctions to hold sway in personal and religious matters. In a sense it undergirded and legitimized the personal and private spheres as sites of an individual's own construction of meaning. It is also one that still not unknown to cultural researchers (see: Leschke and Friesen, forthcoming): This is hermeneutics as the science and art of interpretation.

\section{The School, the Media-System and Social Distinctions}

After academics and educators secured writing as their Leitmedium, they had to defend both writing as an enculturated medium as well as the culture and values which it had been so invisibly but powerfully integrated. At the same time, these educators had to maintain the privileged status of interactive oral discourse as a kind of mediatic ideal. Both pure orality and a rarefied textuality had, each in their own way, to be regarded as positive, despite the many differences that separated them. This includes not only the fact that both belong to different epochs in the history of media, but also that the latter (textuality) has long taken the place of the former (orality) as the cultural Leitmedium in the west. The tension arising from the different types of privilege ascribed to written and oral media is an important one that has been little examined (see Giesecke 1991, 29-36 and Friesen 2013 for two exceptions).

In the context of this broad historical timescale, the end of the $19^{\text {th }}$ century represents an important caesura. It is a moment marked by the appearance, over essentially three decades, of the gramophone, film, typewriter and other electromechanical media forms (e.g., the telegraph). The first three of these forms both the focus and title of one of the best-known German texts in media theory, by Friedrich Kittler (1986/1999). In this text Kittler explores how these technologies 
have set into motion a series of challenges to the supremacy of text that are still working themselves out to this day. All the same, it is not surprising that pedagogy has chosen in this context to protect its one and only naturalized Leitmedium against encroachment by all others. In this context, an apocalyptic attitude to new media does indeed become indispensable kind of carry-on baggage, a sort of natural attitude.

The pedagogical reaction to new media also involves strategies of marginalization and interdiction. If it finally becomes impossible to minimize or ignore the rise of a given new medium, then this medium is integrated in a particular way: Its everyday use is made the subject of analytic and empirical study and normative prescription. The advocates and defenders of textuality have taken the media represented by film, radio and television and subjected them to this treatment. At the same time, however, the book remains the medium of reference for this process, the one medium according to which all others are measured. This history of emotionallycharged attacks against new media, the history of censorship and the auto da fé appears fairly consistently over the decades - but these have been only temporary. After a period of time, a given «new» medium makes its appearance as a controlled part of school life and an accepted unit of the academic curriculum. However, all the while, the book always retains its place as the medium of choice and reference; should this status itself change, then the academy would also have to abandon a wide variety of characteristics on which its legitimacy and recognizability currently relies; and it is clearly not yet prepared to do so.

In this sense, the school reproduces a media-system that is not entirely different from that of society in general in terms of its integrative nature, but that is distinct in terms the particular media that it seeks to preserve and privilege. This privilege is sustained through an implicit set of norms through which cultural value is ascribed to various media. The fact that this set of norms has no grounding outside of itself and the book as Leitmedium, and that it reflects the interests of established social actors rather than those of the young and marginalized, makes public debate about new media volatile and emotional. But it is still through such debate that the cultural value of various media forms are negotiated, often resulting in a kind of hierarchy of different media types. Computer games and online social networks, for example, have most recently undergone such emotional, quasi-deliberative processes, and have been integrated into academic studies of culture (e.g. game studies, network analyses) and school «media literacy» programs.

In school and academic settings, the criteria of (inter-)action, reflection and identity originally derived from the medium of the book are applied to new media and to the actors or advocates associated with them. Of course, these processes of negotiation are ones which newer media forms and their advocates enter at a significant disadvantage, and they rarely if ever gain the upper hand. Despite 
this fact, the established media-system of the school has recently and gradually undergone a change from a purely apocalyptic to a more ambivalent position in the context of «media literacy» debates and curricula. As already indicated, the earlier naive refusal of any approach other than one of unmitigated critique of TV, popular music and other new media forms has been abandoned and replaced with a somewhat more open orientation. However, education's conception of the human subject, its criteria for assessing the cultural value of media still follow the Leitmedium of the book. Indeed the term «media literacy» communicates this fundamental ambivalence with both clarity and concision. The movement corresponding with this term represents an attempt to integrate these new and unnaturalized media into the media-system of the school, and from there to develop appropriate responses to them. This task has recently been simplified by the fact that computers, the Internet and social networks (as media theorist Hartmut Winkler [1997] suggests), are all text-based. This gives them a certain structural affinity to the privileged medium of the book.

These publically negotiated mediatic hierarchies generate and guarantee the subtle distinctions of «taste» that Pierre Bourdieu (1984) describes as serving the larger function of reproducing social life and its inequalities. Bourdieu investigates the everyday examples of gestures, ways of sitting in one's living room, and choices of music and cinema made by various demographic groups. These, he says,

owe their specific efficacy to the fact that they function below the level of consciousness and language, beyond the reach of introspective scrutiny or control by the will. Orienting practices practically, they embed what some would mistakenly call values in the most automatic gestures or the apparently most insignificant techniques of the body - ways of walking or blowing one's nose, ways of eating or talking - and engage the most fundamental principles of construction and evaluation of the social world. (466)

Of course, such automatic gestures and apparently insignificant «techniques» of the body have now mutated and expanded to include those required or encouraged by new media. Some have noted, for example, the "genuflected» posture required in using one's mobile phone in public (e.g., Talman, 2013). Others have highlighted the rapid "twitching" characteristic of video game play (e.g., Prensky, 2007) - but which is also evident in adult use of various mobile devices. Bourdieu goes on to explain how these everyday habitual «techniques» and the objects associated with them function as markers of taste and class, and how these matters of taste play a constitutive role in society 
Taste is a practical mastery of distributions which ... functions as a sort of social orientation, a ssense of one's places, guiding the occupants of a given place in social space towards the social positions adjusted to their properties, and towards the practices or goods which befit the occupants of that position. (466)

Through distinctions of taste and the bodily habits and gestures that media encourage, the stratifications and distinctions of the embodied and everyday social world are reshaped and restructured. The type of marking and structuring offered by digital media, as argued below, differ significantly from those of the old.

\section{The Book as Media-Dispositif}

Traditional media-systems are constituted by an established number of individual media. To use a Foucauldian term, we can say that each individual medium represents an autonomous dispositif. This refers to a kind of «apparatus», a system of relations that includes both discursive and non-discursive interactions, components and manifestations of knowledge. At their point of intersection they can be said to constitute what Foucault describes as a «thoroughly heterogeneous ensemble» $(1977,194)$ - which can take the form of a particular media technology or artifact. Giorgio Agamben explains that such an apparatus or dispositif has multiple capabilities, including

[The] capacity to capture, orient, determine, intercept, model, control, or secure the gestures, behaviors, opinions, or discourses of living beings. [This apparatus] therefore not only includes] prisons, madhouses... schools... and so forth (whose connection with power is in a certain sense evident), but also the pen, writing, literature, philosophy, agriculture, cigarettes, navigation, computers, cellular telephones and - why not - language itself, which is perhaps the most ancient of apparatuses. $(2009,14)$

The relevance of the apparatus or dispositif to media forms can be fairly easily illustrated through the example of the Leitmedium of the book. The folded pages of a book or codex, by their very physical nature, signal a clearly demarcated beginning and end, and indicate the amount of text lying between them. Unlike an ancient scroll or a scrolling Web page, the book suggests its closed and determinate nature to the reader as soon as he or she lays eyes on it. The book generally takes the reader through these pages in linear fashion, chapter by chapter, page by page and line by line, offering a highly organized and conventionalized presentation. Due to the pervasive nature of Medienvergessenheit discussed above, the book and its parts are generally not examined in this way in either theory or philosophy. 
Instead, particularly in British empiricism, it has been used to exemplify a discrete, indubitable sensory object - highlighting precisely its determinate self-sufficient character. And this is done without giving a moments' thought to the constructed and culturally contingent nature of the book as an orienting epistemic metaphor or dispositif. The components and associated technologies of the book reappear with remarkable frequency as hypothetical cases according to which other questions of perception and ultimately, truth, are to be resolved. Locke, for example, imagines a stranger to the West being introduced to this object and its parts; being «told that all learned books consisted of paper and letters, and that letters were things inhering in paper, and paper a thing that held forth letters: a notable way of having clear ideas of letters and paper $(1877,117) . »$ Later, Bishop Berkeley casts doubt on such reasoning through references to the indubitability of both books and (im)printing: "Can extended things be contained in that which is unextended?» Berkeley then answers: "You cannot say objects are in your mind, as books in your study: or that things are imprinted on it, as the figure of a seal upon wax"(1843, 273). William James later provides a pragmatist response to such arguments by considering the following: "The book here lying on the table before me, and the book in the next room of which I think and which I mean to get, are both in the same sense given realities for me, realities which I acknowledge and of which I take account» (James, 1904, 480).

As Berkeley's remarks suggest, the exemplary object of the book can be unambiguously closed and shelved with other books like it - something which is often done alphabetically by the author's last name. Particularly in academic contexts, the author, his/her words and arguments, and the book effectively become one, forming a highly flexible synecdoche: The Riverside Shakespeare is Shakespeare, a set of volumes on the shelf will be Dickens, embodying these identities with an authority, and a sense of finality and closure that is also public as the word publish suggests. This consummates the finality and authority of the «work» as an individual and closed object. Patrick Bazin describes what has been referred to as "the order of the book» in a way that extends this description and also resonates with the Foucauldian dispositif as described above:

[It is] a fundamental constraint that structures modernity's mental space: one which prescribes that text within the book be linear, and, especially, that it have a beginning and end... the book shrugs off all confusion between language and world, reality and representation; it intrinsically aims for effects of truth (of which literary fiction in particular is at bottom only the inverted double). [...] the book sets the stage for a trilogy - author, book, reader based on the separation of roles and a stability: on the one hand, the author, on the other, the reader, each exchanging their singularities through the stable, reliable, and public «interface» of the book. $(1996,159)$ 
The media-system extant at a given point in history is nothing more than the set of such interfaces or media-dispositifs that happen to be available at the time. Movements and changes in traditional media-systems can be said to have occurred through the addition or exchange of these single-media-dispositifs. The dispositif represented by the codex or by another medium (e.g. dramatic recitation of a text or a hand-written scroll) could compete with these, very gradually but incontrovertibly replacing others or itself being replaced. A single medium, and by extension, its corresponding dispositif, could be selected from the existing mediasystem, and in theory, be identified as a Leitmedium or medium of reference in a particular context. This can be seen to be the case with composer Richard Wagner or philosopher Henri Bergson: For the former, musical forms undergirded his use of a range of other media forms (textual, dramaturgical, etc.) to constitute the Gesamtkunstwerk. Bergson on the other hand used metaphors based on the then newly-invented medium of cinema to develop his vitalist philosophy of change, motion and growth.

\section{Digitized Media \& Performativity}

The digitization of media - whether of text, music, photography, film, etc.represents a profound revision of media-systems and the dynamics of their construction. Of course, this does not mean that the digitalization of media, as some had predicted, has led to a general compatibility and interoperability of all media, and thus to the complete dissolution of carefully protected dispositifs of individual media. Instead, the ensemble of these dispositifs appears to have imploded, forming what can be called a «transversally-integrated» media-system, in which individual media and their dispositifs have only a virtual existence. Such an existence maintains only the effect of the differences between them. No longer physical or material (e.g., music on a stereo system, film on a projector, video on a TV/VCR), the differences between media are instead essentially aesthetic. If one today engages with radio, TV, film, games or social media, such engagement generally occurs through the same interfaces of screen, keyboard and pointer (or their touch-screen equivalents), and the difference between these media is largely a question of cultural or aesthetic conventions, rather than of the technology or materiality of any associated product. Our media-system today is consequently no longer an ensemble of completely heterogeneous technologies, platforms and processes. It is instead a system of differences defined virtually, culturally and aesthetically for which there is no longer any controlling or overarching material limitation or necessity. It is in this sense that it is "transversally» - associatively rather than physically or hierarchically - integrated. Our media-system, then, is actually a system of conventions, each of which owes its existence to much earlier processes of enculturation of traditional, non-virtual media-systems. 
Reference to virtual media does not occur with the ineluctable and irrefutable certainty as it does with technologically closed and materially-encumbered mediadispositifs. Individual, physical media, in this sense, have lost their power to persuade and convince, and also their ability to ground thought, truth, place and certainty (e.g., with a closed book on the shelf authoritatively being Shakespeare). Furthermore, it no longer makes sense to try to secure an old or new Leitmedium for education, and to then highlight and privilege its characteristics when those of another medium present a challenge. It is also just as risky to associate the identity of particular groups in society with these fragile and changeable virtual constructions that were at one time so stable and definitive. In this sense the relationship between social and medial differences and distinctions is changed at its very core. In traditional media-systems there was at least some reliable ordering and association, as there was, for example, between the book and the educated bourgeoisie, the personal library and the enlightened aristocrat, or reality TV and the working-class viewer. Instead, the reference for social distinctions can only be constituted through the media-system as a whole. The magazine or book being perused disappears behind the back of a e-reader device; and with the earlier disappearance of the transistor or portable radio, the music now playing on one's invisible portable player is similarly rendered inaudible (for this not to be the case is in many cultural contexts a breach of social etiquette). Social and cultural differences no longer parallel differences in the use of specific media, but instead are based on the style and efficiency of the use made of the media-system as a whole. In a post-conventional, transversally interconnected media-system, the content of any work or of any individual medium is not particularly important; what matters instead is the style of one's performance across the media-network.

Differences and distinctions have become consequently more subtle and evasive, but despite this, they are no less important. It is becoming well-neigh impossible to signal social-cultural differences reliably: One must be able to work with ever finer distinctions in knowledge domains that are unstructured, and to engage with varying degrees of «fuzziness» or ambiguity generated through masses of information. The ability to tolerate ambiguity and reduce complexity are qualifications that are indispensable for effective performance in digitized media-systems. With complexity-reduction, information-selection and tolerance of ambiguity as the bases of medial performance, the hermeneutic logic of meaning, depth, interiority, wholeness and (self)-identity falls by the wayside. What takes its place are operations of differentiation, identification, combination and recombination, of association and application. Interpretation and hermeneuticallygenerated knowledge require closed and isolated objects (books, codices, «works», or even silently reading persons) in order to function properly; and it is precisely these characteristics that are irretrievably lost in transversally-networked 
media-systems. That the hermeneutic orientation still retains its legitimacy in school settings reflects the fact that these settings are based on antiquated media and systems, ones which can only exist in protected environments, as in a kind of cultural bubble. The idea that at the end of ones schooling, one should be able to solve problems largely without reference to media - an idea which grounds any regime of standardized and high-stakes testing - is a familiar illustration of this situation.

This is all part of a transition from an orientation based on content to one based on form - from collections, cannons and repertories to genres, types and structures. Unlike media content, forms offer a key way of reducing the complexity of cultural products. Replacing the singularity of the author are elements which are always multiple and redundant --particularly seriality and structure. Indeed the centrality of form can be said to have replaced the authority of the author or creator him- or herself. Knowledge of the author in his or her singularity is replaced by the ability to recognize and deal reliably with multiple media forms - which range from sites of media consumption (e.g. library vs. cinema) to genre, style and other expressive conventions. Since the introduction of mass production in manufacturing, mediasystems have worked with repetition and serial variation as a key ingredient. There are only a few sub-domains of high culture and schooling that have managed to suppress these characteristics, and thus are able to maintain media-systems in which singularity and self-sufficiency remains central.

The implicit knowledge of forms central to digital media is currently ignored by education. It remains unformalized and unsystematized, and consequently can currently be acquired only as «wild» knowledge collected on the street, as it were. Knowledge of the combinatory logic of serial drama, of game engines, and of the media and genre conventions interconnecting transversal media is currently mostly unreflected, unconscious and tacit. Systems of education which ignore these forms can be said to prepare students only for marginalized and historical modes of aesthetic and cultural production. These same students are consequently subjects with a sense of interiority and relatively static self-identity; by implication, however, they are also not performative subjects able to construct and regulate identity in diverse media environments and for different media audiences and purposes.

As the order of the book gradually dissolves, and the question of performance and performativity becomes increasingly important, the topography of education and individual (self-)development is also transformed. Socrates' dictum to «know oneself» is no longer an exercise in writing oneself and one's knowledge onto the pages of a (exercise) book - and in memorizing it for a test. As the media that mediate culture continue to change, and these changes reshape social reproduction, the skills and abilities requisite to their use, navigation and evaluation also change. As a multiplicity of Google search results leaves the authority of the singular author or 
source ever further behind, it is the performance of the search and the subsequent reduction of complexity that becomes indispensable. Reproducing the skills and abilities requisite to such a performance in the complex, combinatory digitalized environment becomes a key educational task.

\section{References}

Agamben, Giorgio. 2009. What is an Apparatus? And other Essays. Stanford: Stanford UP.

Bazin, Patrick. 1996. «Toward Metareading.»In The Future of the Book, ed. Geoffrey Nunberg, 153-169. Berkeley: University of California Press.

Berkeley, George. 1843. The Works of George Berkeley. Vol. 1. London: T. Tegg.

Bourdieu, Pierre. 1984. Distinction: A Social Critique of the Judgement of Taste. Cambridge MA: Harvard UP.

Enzensberger, Hans M. 1978. "Two Notes on the End of the World: Remarks on the Spectacle.» New Left Review I (110): 74-80.

Foucault, Michel. 1980. "The Confession of the Flesh.» In Power/Knowledge Selected Interviews and Other Writings, ed. Colin Gordon, 194-228. New York: Pantheon.

Friesen, Norm. 2013. «Media, Pedagogy, Normativity and Norms.» In Normativität und Normative (in) der Pädagogik, ed. Thorsten Fuchs, May Jehle and Sabine Krause. Würzburg: Königshausen \& Neumann.

Giesecke, Michael. 2002. Von den Mythen der Buchkultur zu den Visionen der Informationsgesellschaft: Trendforschung zur aktuellen Medienökologie. Frankfurt: Suhrkamp.

Giesecke, Michael. 1991. Der Buchdruck in der frühen Neuzeit. Frankfurt: Suhrkamp. Horn, Eva. 2008. «Editor's Introduction: 〈There are no media.»» Grey Room 29: 6-13. James, William. 1904. «Does ¿Consciousness〉 Exist?» Journal of Philosophy, Psychology, and Scientific Methods, 1, 477-491. http://psychclassics.yorku.ca /James/consciousness.htm.

Krämer, Sybille. 2008. Medium, Bote, Übertragung: Kleine Metaphysik der Medialität. Frankfurt: Suhrkamp.

Leschke, Rainer. 2008. «Medienformen und Medienwissen. Zwischen Interpretation und Formerkennung.» In Media, Knowledge \& Education. Exploring new Spaces, Relations and Dynamics in Digital Media Ecologies, ed. Theo Hug, 36-50. Innsbruck: Innsbruck University Press.

Leschke, Rainer. 2010. Medien und Formen: Zu einer Morphologie der Medien. Konstanz: UVK.

Leschke, Rainer. 2011. «Von der Auflösung der Medien in der Universalität der Medialität.»In medias in res: Medienkulturwissenschaftliche Positionen, ed. Till A. Heilmann, Anne von der Heiden, Anna Tuschling, 69-81. Bielefeld: Transcript. 
Leschke, Rainer und Norm Friesen (in press). «McLuhan and Medienwissenschaften. Sense and Sensation.» Media Transatlantic: Media Theory in Canada \& GermanSpeaking Europe. Amsterdam: Rodopi.

Locke, John. 1877. An Essay Concerning Human Understanding. London: William Tegg and Co.

Plato. 1892. The Dialogues of Plato. Ed. B. Jowett. Vol. 1. $3^{\text {rd }}$ ed. Oxford: Oxford University Press.

Prensky, Marc. 2007. Digital Game-Based Learning. New York: Paragon House.

Talman, Hugh. 2013. Cell Phone Genuflection (Photo). http://www.flickr.com/photos /tallphoto/9048611991/.

Winkler, Hartmut. 1996. Docuverse: Zur Medientheorie der Computer. Munich: Boer. 